\title{
Maternal awareness of the association between paediatric diet and adult disease risk: A follow-up to the DIT-Coombe Hospital Study
}

\author{
Q. Zhou, K. M. Younger and J. M. Kearney \\ School of Biological Sciences, Dublin Institute of Technology, Kevin Street, Dublin 8, Republic of Ireland
}

Chronic disease has been traditionally attributed to risk factors in adulthood; however, current orthodoxy suggests that the true origins of such diseases are initiated much earlier in life from inappropriate nutritional circumstances arising during the formative years ${ }^{(1)}$. The present study was undertaken to examine current maternal attitudes towards the importance of paediatric diet in relation to adult diseases and to determine the extent to which attitudinal differences between subgroups in the population exist.

A non-randomised postal follow-up survey to the DIT-Coombe Hospital Infant Feeding Study was carried out, involving the recruitment of 209 mothers from a pool sample of 520 mothers in the previous study ${ }^{(2)}$ (response rate $46.7 \%$ ). Quantitative data were obtained from a cross-sectional questionnaire ranking maternal attitudes towards infant diet on a five-point Likert scale ${ }^{(3)}$ (from strongly disagree to strongly agree) of perceived importance.

In general, a higher percentage of respondents (64) had a cumulative positive view of the relationship between paediatric diet and disease risk. Of the mothers $>70 \%$ expressed a strong positive attitude towards the influence of early childhood diet and the risk of being overweight, poor growth and development, unhealthy food preference, osteoporosis, diabetes, high blood pressure and heart disease. In comparison, cancer, eczema and food allergies were viewed positively overall but the extent to which individuals most strongly agreed with each fell to $<50 \%$. The majority had a negative opinion (either disagreed strongly or tended to disagree) of the importance of paediatric diet in mental health problems. According to one-way ANOVA analysis, attitudinal differences in mean scores $(P<0.05)$ were observed in mothers according to age at time of birth, education level, accommodation status and health insurance status, as well as the timing of weaning (Table).

\begin{tabular}{|c|c|c|c|}
\hline Subgroups & Mean score & $P$ & $\begin{array}{l}\text { Diseases perceived to be } \\
\text { influenced by infant diet }\end{array}$ \\
\hline \multicolumn{4}{|l|}{ Age at time of birth (years) } \\
\hline $15-24$ & 3.00 & 0.001 & Heart disease \\
\hline $25-34$ & 3.77 & & \\
\hline$>34$ & 4.04 & & \\
\hline \multicolumn{4}{|l|}{ Education level } \\
\hline Primary or secondary level & 3.93 & 0.012 & Unhealthy food preference \\
\hline Vocational or training course, VEC or FAS & 4.02 & & \\
\hline Third level including postgraduate & 4.27 & & \\
\hline \multicolumn{4}{|l|}{ Accommodation status } \\
\hline House or apartment owners & 4.30 & 0.030 & Overweight \\
\hline Non-house or apartment owners & 3.97 & & \\
\hline \multicolumn{4}{|l|}{ Health insurance status } \\
\hline Public & 3.95 & 0.018 & Unhealthy food preference \\
\hline Semi-public & 4.26 & & \\
\hline Private & 4.34 & & \\
\hline \multicolumn{4}{|l|}{ Timing of weaning } \\
\hline$\leq 12$ weeks & 3.59 & 0.032 & Diabetes \\
\hline$>12$ weeks & 4.00 & & \\
\hline
\end{tabular}

The results indicate that mothers who are younger and less educated, as well as those who wean their child before 12 weeks after birth should be targeted for further health education on the specific benefits of infant diet, which may in turn contribute towards relieving the strain of chronic disease on society.

1. Barker DJP, Erikson JG, Forsen T \& Osmond C (2002) Int J Epidemiol 31, 1235-1239.

2. Tarrant RC, Younger K, Sheridan-Periera M \& Kearney JM (2007) Proc Nutr Soc 66, 54A.

3. Nayak L \& Erinjeri JP (2008) Acad Radiol 15, 383-389. 